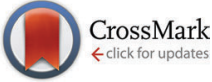

Cite this: New J. Chem., 2016, 40, 8892

Received (in Montpellier, France) 2nd June 2016,

Accepted 2nd September 2016

DOI: 10.1039/c6nj01736c

www.rsc.org/njc

\title{
Calixarenes with naphthalene units: calix[4]naphthalenes and hybrid[4]arenes $\uparrow$
}

\author{
T. Boinski, ${ }^{a}$ A. Cieszkowski, ${ }^{a}$ B. Rosa, ${ }^{a}$ B. Leśniewska ${ }^{b}$ and A. Szumna*a
}

\begin{abstract}
Macrocycles consisting of naphthalene units connected via methylene bridges offer certain advantages as macrocylic scaffolds as compared with parent calixarenes. These advantages originate from their electron rich and enlarged cavities. Additionally, macrocycles containing 1,3-bridged naphthalene units are dissymmetric and therefore they present interesting stereochemical features, including inherent chirality. We describe here a facile, one-step synthesis of two new calix[4]naphthalenes, by the condensation of 1,6-dimethoxynaphthalene with formaldehyde catalyzed by Brønsted acid (TFA). Additionally, we show the first example of hybrid[n]arene containing a 1,6-dimethoxynaphthalene unit and 1,3-dimethoxybenzene units obtained by a simple, one-pot condensation. The conformational and complexation properties were also studied for the resulting hybrid macrocycles.
\end{abstract}

\section{Introduction}

The emergence of a new versatile macrocyclic building block that enables build-up of the functional architecture on its semi-rigid scaffold often ignites new research directions in supramolecular chemistry and many related areas. Versatile macrocycles like calix $[n]$ arenes, cucurbit $[n]$ urils, cyclodextrines, cyclotriveratrylenes and calixpyrroles have been discovered decades ago and widely exploited since then. ${ }^{1}$ For years chemists concentrated on the functionalization of the existing scaffolds rather than on hunting for new ones, because the existing scaffolds offered almost unlimited possibilities. However, with the discovery of pillar[5]arene, a completely new, yet simple and very useful macrocylic building block, by the group of Ogoshi and Nakamoto in $2008,{ }^{2}$ the quest for new polyphenolic macrocycles has received a new inspiration. Since then the group of Stoddart obtained a family of electron-rich macrocycles known as asar $[n]$ arenes. ${ }^{3} \mathrm{We}^{4}$ and others $^{5-10}$ have synthesized a family of hybrid $[n]$ arenes containing different polyphenols embedded within one macrocycle. Many new non-phenolic methylene-bridged macrocycles have also been synthesized recently, for example calix[3]carbazoles. ${ }^{11}$ Great interest in new macrocycles and their almost immediate applications indicate that new semi-rigid supramolecular scaffolds are still sought-after.

\footnotetext{
${ }^{a}$ Institute of Organic Chemistry, Polish Academy of Science, Kasprzaka 44/52, 01-244 Warsaw, Poland. E-mail: agnieszka.szumna@icho.edu.pl

${ }^{b}$ Institute of Physical Chemistry, Polish Academy of Science, Kasprzaka 44/52, 01-244 Warsaw, Poland

$\dagger$ Electronic supplementary information (ESI) available: NMR and ESI MS spectra, titration experiments. CCDC 1474998. For ESI and crystallographic data in CIF or other electronic format see DOI: 10.1039/c6nj01736c
}

Calix $[n]$ naphthalenes, i.e. macrocycles consisting of naphthalene units connected via methylene bridges at their meta-positions, may offer some advantages as macrocylic scaffolds originating from enlarged cavity with electron rich aromatic surfaces. Additionally, due to naphthalene geometry, the resulting macrocycles are dissymmetric and therefore they may present interesting stereochemical features, including inherent chirality. Indeed, extended cavity features of calix $[n]$ naphthalenes have been exploited for the complexation of fullerenes. ${ }^{12}$ However, the number of the family members of calix $[n]$ naphthalenes is small. They include macrocycles obtained from 1-hydroxynaphththalene ${ }^{13}$ and 2-hydroxynaphthalene $^{14}$ and various macrocycles obtained from 2,7-dialkoxynaphthalenes ${ }^{15,16}$ or chromotropic acid. ${ }^{17}$

Recently, we have found that methylene bridged polyphenolic macrocycles, for example pillar[5]arenes and hybrid[4]arenes, can be synthesized by a Brønsted acid-mediated direct reaction of alkoxybenzenes with formaldehyde. ${ }^{4,18}$ The important finding was that the reaction is reversible when it is catalysed by a Brønsted acid (TFA in that case). It enabled an efficient solventtemplated synthesis of deca-O-alkylpillar[5]arenes and rearrangements of already-formed homo-macrocycles to thermodynamically preferred hybrid macrocycles. In the current paper we show that such thermodynamically controlled reactions can be used not only for substrates containing single aromatic rings but also for the formation of new naphthalene-based macrocycles.

\section{Results and discussion}

In order to obtain hybrid macrocycles containing naphthalene units we have used a one pot TFA-catalysed macrocylization reaction of formaldehyde with 1,6-dimethoxynaphthalene $\mathbf{1 b}$ 


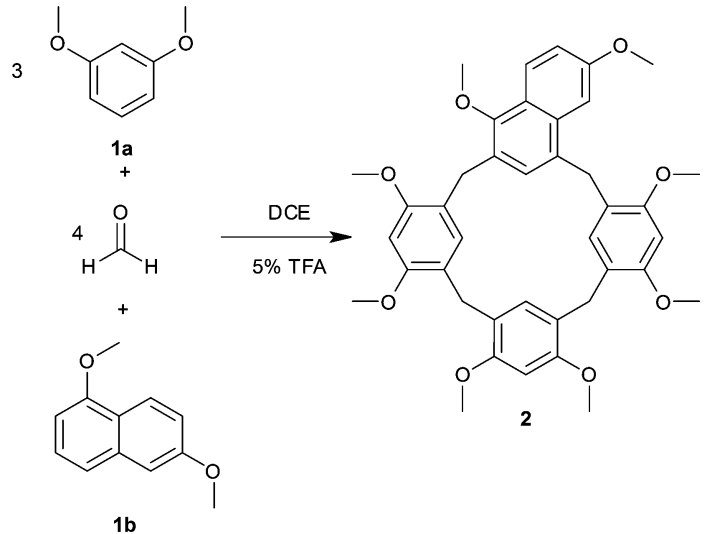

Fig. 1 Synthesis of hybrid[4]arene 2 .

and 1,3-dimethoxybenzene 1a (Fig. 1). Our initial approach concentrated on macrocycles having the same number of units of each type, therefore we have used a 1:1 ratio of polyphenolic building blocks. However, in this case we observed the preferential formation of a macrocycle that contains one 1,6-dimethoxynaphthalene unit and three 1,3-dimethoxybenzene units, as it was established based on the NMR spectrum and mass spectrometry. ${ }^{1} \mathrm{H}^{13} \mathrm{C}_{\mathrm{HSQC}}$ and ${ }^{1} \mathrm{H}_{-}{ }^{13} \mathrm{C}$ HMBC spectra indicate that methylene bridges link the macrocycle at 2,4 positions of the naphthalene unit, suggesting structure 2 . Considering the $[1+3]$ stoichiometry of product 2 we adjusted the stoichiometry of reagents accordingly. This way hybrid [1+3] macrocycle 2 was obtained in $47 \%$ yield.

Since 1,6-dimethoxynaphthalene $\mathbf{1 b}$ has not been previously used in macrocylization reactions with formaldehyde, we have also tested it under the conditions that may lead to the formation of homo-macrocycles. The reaction of 1,6-dimethoxynaphthalene 1b with formaldehyde in DCE catalysed by TFA gave two main products in similar yields, both of them being tetramers, as indicated by mass spectrometry. One of the products exhibits highly symmetric ${ }^{1} \mathrm{H}$ and ${ }^{13} \mathrm{C}$ NMR spectra with only a single 1,6dimethoxynaphthalene unit being symmetrically independent. ${ }^{1} \mathrm{H}_{-}{ }^{13} \mathrm{C}$ HSQC and ${ }^{1} \mathrm{H}_{-}{ }^{13} \mathrm{C}$ HMBC spectra suggest that methylene bridges link the macrocycle at 2,4 positions of the 1,6-dimethoxynaphthalene unit, thus the product has $C_{4}$-symmetric structure 3 (Fig. 2). In contrast, ${ }^{1} \mathrm{H}$ and ${ }^{13} \mathrm{C}$ NMR spectra of the second tetrameric product show that all 1,6-dimethoxynaphthalene units are symmetrically non-equivalent. Analysis of $2 \mathrm{D}$ NMR spectra suggests a $C_{1}$-symmetric structure, $\mathbf{4}$, for the second tetrameric product (Fig. 2). Calix[4]naphthalene 4 is a regioisomer of calix[4]naphthalene 3 and differs by the orientation of a single naphthalene unit. The optimization of the synthetic procedure by changing the concentration, solvent, reaction time and amount of catalyst resulted in obtaining $\mathbf{3}$ and $\mathbf{4}$ in a maximum yield of $15 \%$ each (Table 1 ).

Calix $[n]$ arenes exhibit various degrees of conformational flexibility that depend mainly on steric hindrance within macrocyclic rings and on additional interactions (e.g. stabilizing intramolecular hydrogen bonding). For calixarenes existing in fixed or slowly interconverting (at the NMR timescale) cone

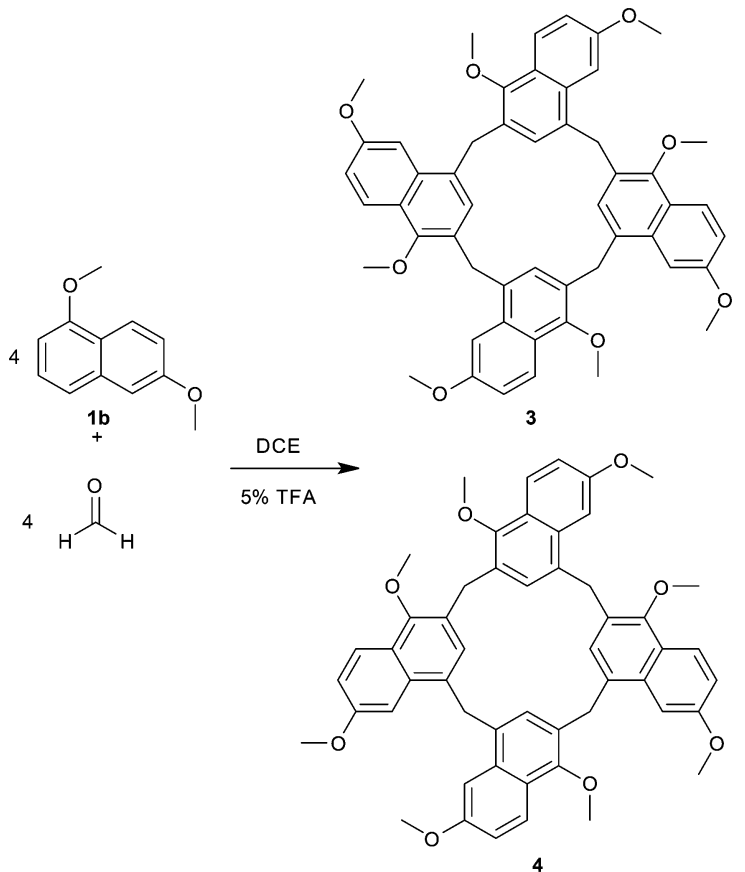

Fig. 2 Synthesis of calix[4]naphthalenes 3 and 4.

Table 1 Optimization of the synthesis of $\mathbf{3}$ and $\mathbf{4}$

\begin{tabular}{lllllll}
\hline Entry & Solvent & $C$ of $\mathbf{1 b} / \mathbf{M}$ & Time/h & TFA/\% & Yield of $3 / \%$ & Yield of $\mathbf{4} \%$ \\
\hline 1 & DCE & 0.1 & 18 & 5 & 12 & 13 \\
2 & DCE & 0.1 & 4 & 5 & 14 & 12 \\
3 & DCE & 0.1 & 2 & 5 & 15 & 15 \\
4 & DCE & 0.5 & 2 & 5 & 8 & 9 \\
5 & DCE & 0.025 & 2 & 25 & 14 & 15 \\
6 & DCE & 0.1 & 1 & 1.25 & 8 & 7 \\
7 & CHCl & 0.1 & 2 & 5 & 13 & 15 \\
8 & DCE & 0.1 & 2 & 40 & 10 & 12 \\
9 & DCE & 0.1 & 2 & 20 & 12 & 13 \\
10 & DCE & 0.1 & 2 & 2 & 11 & 12 \\
11 & DCE & 0.1 & 2 & 1 & 5 & 6
\end{tabular}

conformations the bridging methylene protons are found as a pair of doublets in the NMR spectra. Here, for macrocycles 2-4 the methylene bridges are found as broad singlets in their NMR spectra at $303 \mathrm{~K}$ (ESI $\dagger)$. Moreover, at $218 \mathrm{~K}$ the signals get broader but they do not split (ESI $\dagger$ ). It indicates that the macrocyclic rings either: (i) exhibit conformations rapidly inverting on the NMR time scale or (ii) exhibit static conformations with geminal protons related by symmetry. Due to a substitution pattern of the building units and the fact that a planar structure of the macrocycle is not possible, we conclude that symmetrybased relationship between geminal protons is not possible. Therefore, the macrocyclic 16-membered rings reported here exhibit dynamic conformations in solution, similar to other calixarenes that are devoid of stabilizing hydrogen bonding interactions, i.e. $\mathrm{OH}-d e p l e t e d$ calix[4]arenes and per-O-alkylated resorcinarenes. The current findings are also in agreement with our previous conclusions for hybrid $[n]$ arenes, which claimed considerable conformational flexibility of 1,3-bridged units 
within medium-sized macrocyclic rings. ${ }^{4}$ Conformational lability of macrocycles 2-4 determines their stereochemical properties. Due to dissymmetric naphthalene substitution patterns, macrocycles $\mathbf{2 - 4}$ have a possibility to exhibit inherent chirality. However, inherent chirality additionally requires hindered rotation about single bonds in order to block eversion of macrocyclic rings. ${ }^{19}$ For macrocycles 2-4 the rotation about single bonds is not hindered, so the current products are achiral. However, in the presence of a proper guest or after a chemical modification that will hinder the rotation, macrocycles $\mathbf{2 - \mathbf { 4 }}$ can become chiral.

We were able to grow single crystals of $\mathbf{4}$ suitable for X-ray analysis. In the solid state $\mathbf{4}$ exhibits a boat conformation with two opposite naphthalene rings positioned orthogonally to the main macrocyclic plane and almost parallel to each other (Fig. 3). Interestingly, two methyl substituents from the parallel naphthalene units point towards the cavity and towards the opposite lying aromatic rings. This $\mathrm{CH} \cdots \pi$ interaction seems to be favourable and stabilizing for this conformation. The other two naphthalene rings are positioned roughly within the plane of the macrocyclic ring, however, they are substantially distorted.

Even though macrocycle $\mathbf{4}$ possesses a very small cavity in the boat conformation found in the solid state, the dynamic character of the macrocyclic ring in solution may enable guest complexation. The recognition properties of macrocycles $\mathbf{2 - 4}$ were tested using guests rac-5 and $\mathbf{6}$ containing imidazolium and pyridinium ions respectively (Fig. 4). The guest molecules were chosen using the criterion of importance (the vast presence of imidazolium and pyridinium fragments in bioactive substances and in structural motifs of topologically bound molecules) and possible favourable non-covalent interactions between electronrich aromatic walls and organic cations (cation- $\pi$ interactions). Initial screening was done using equimolar mixtures of the host and the guest in $\mathrm{CDCl}_{3}$. For both guests rac-5 and 6 a complexation induced shift was detected upon interaction with hosts 2-4 (Fig. 5-7). For guest rac-5 the changes were the most pronounced during the interaction with all hosts. In all cases $\mathrm{H}_{\mathrm{c}}$ protons of rac-5 exhibited a downfield shift, while protons $\mathrm{H}_{\mathrm{a}}$ and $\mathrm{H}_{\mathrm{b}}$ exhibited upfield shifts. The downfield shift of protons is usually observed during the formation of hydrogen bonds or during interactions with edges of $\pi$-surfaces, while the upfield shift is often observed for interactions with central parts of $\pi$-surfaces. In the current case hydrogen bonding is less likely

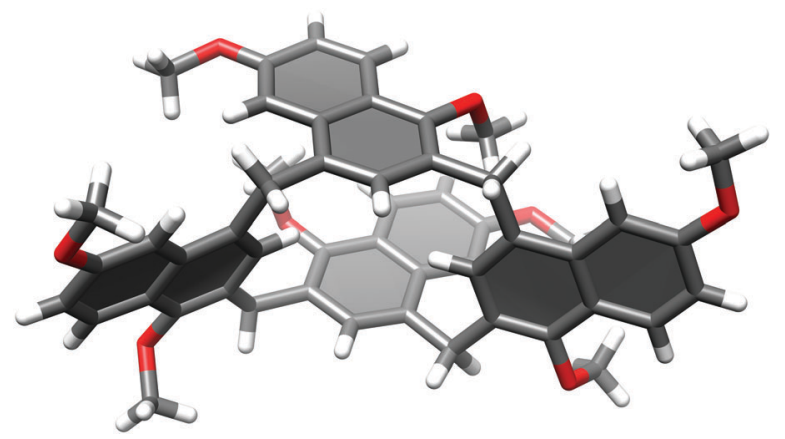

Fig. 3 X-ray structure of $\mathbf{4}$ (for the ORTEP plot see Fig. S1, ESI $\dagger$ ). a)

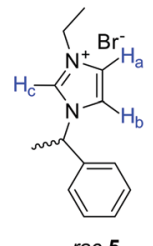

b)
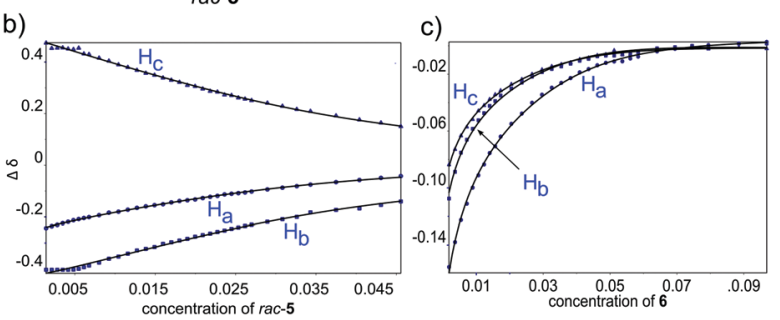

Fig. 4 Complexation studies: (a) chemical structures of the guests; (b) titration of 3 by rac $-5\left(\mathrm{CDCl}_{3}, 298 \mathrm{~K}, \mathrm{C}(\mathbf{3})=15.5 \mathrm{mM}\right)$; (c) titration of 3 by $6\left(\mathrm{CDCl}_{3}, 298 \mathrm{~K}, \mathrm{C}(3)=14.4 \mathrm{mM}\right)$. Points represent experimental data, lines represent fitted curves.
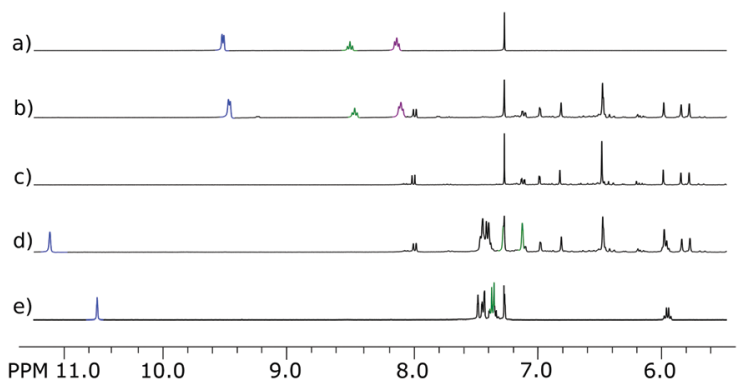

Fig. 5 Complexation properties of hybrid[4]arene 2 : (a) $\mathbf{6}$; (b) $\mathbf{2}+\mathbf{6}(C(\mathbf{2})=$ $14.41 \mathrm{mM}, \mathrm{C}(\mathbf{6}) 15.64 \mathrm{mM}) ;(\mathrm{c}) \mathbf{2}$; (d) 2 + 5 (C(2) = $15.49 \mathrm{mM}, \mathrm{C}(\mathbf{5})=15.63 \mathrm{mM})$; (e) 5 (all in $\mathrm{CDCl}_{3}$ at $298 \mathrm{~K}$ ).

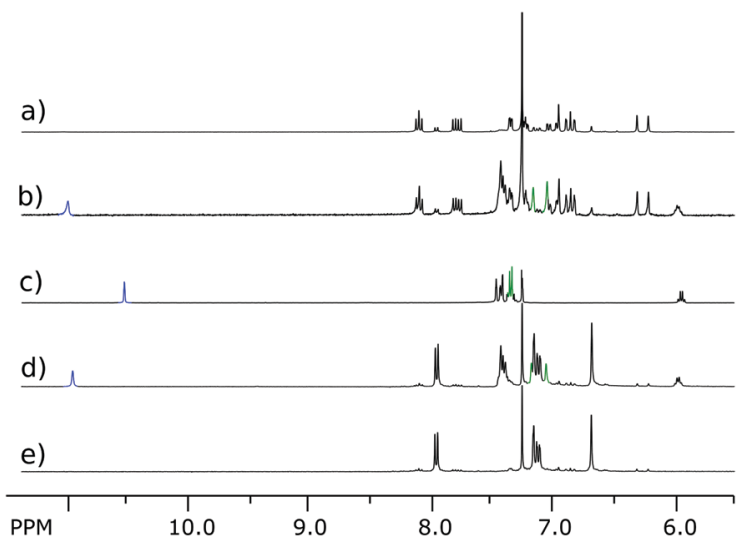

Fig. 6 Complexation of 5 by calix[4]naphthalenes: (a) 4 ; (b) $4+5(C(4)=$ $5.36 \mathrm{mM}, \mathrm{C}(\mathbf{5})=5.23 \mathrm{mM})$; (c) 5; (d) $\mathbf{3}+\mathbf{5}(\mathrm{C}(\mathbf{3})=15.49 \mathrm{mM}, \mathrm{C}(\mathbf{5})=15.49 \mathrm{mM})$; (e) 3 (all in $\mathrm{CDCl}_{3}$ at $298 \mathrm{~K}$ ).

and we suggest that the observed changes come mainly from the interactions between the electron-rich $\pi$-surfaces of the hosts and the electron-poor $\pi$-surface of $r a c-5$.

Interactions between electron-rich and electron-poor aromatic surfaces may involve the formation of a charge-transfer complex 

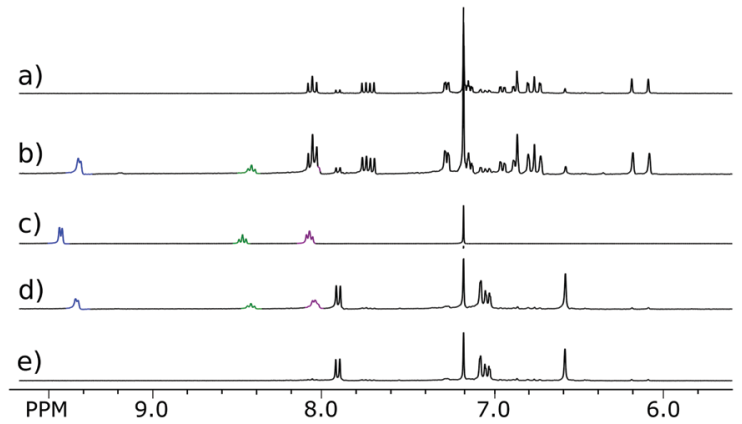

Fig. 7 Complexation of 6 by calix[4]naphthalenes: (a) 4 ; (b) $4+6(C(4)=$ $7.03 \mathrm{mM}, C(6)=6.99 \mathrm{mM})$; (c) 6; (d) $3+6(C(3)=14.43 \mathrm{mM}, C(6)=15.63 \mathrm{mM})$; (e) 3 (all in $\mathrm{CDCl}_{3}$ at $298 \mathrm{~K}$ ).
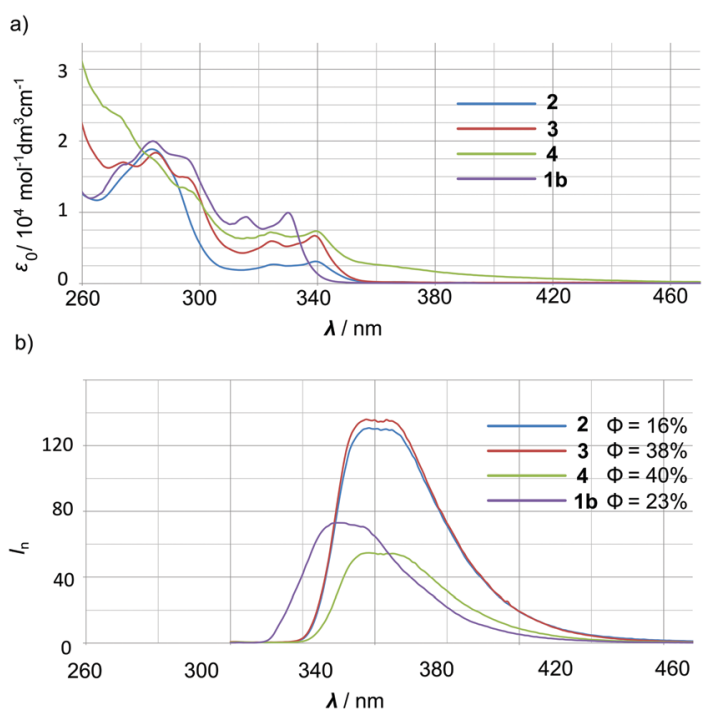

Fig. 8 UV/Vis (a) and fluorescence (b) spectra of macrocycles 2-4 and reference compound $\mathbf{1 b}$ (all in $\mathrm{CHCl}_{3}$ at $298 \mathrm{~K}$ ).

and induce substantial changes in the UV/Vis spectra. Additionally, due to the presence of a 1,6-dimethoxynaphthalene unit the macrocycles exhibit fluorescence. The UV/Vis and fluorescence spectra were recorded for macrocycles 2-4 (Fig. 8), their complexes with rac-5 and 6 (Fig. S36-S42, ESI $\dagger$ ) and $\mathbf{1 b}$ as a reference. Examination of the possible appearance of new CT bands, shifts of the existing bands in UV/Vis and fluorescence spectra, changes in molar absorption coefficients or quantum yields did not show considerable changes upon complexation. These results indicate that charge transfer processes are not pronounced for current complexes.

Association constants were determined by ${ }^{1} \mathrm{H}$ NMR titration followed by a non-linear curve fitting as implemented in HYPNMR. ${ }^{20}$ All signals that exhibited detectable changes in chemical shifts were fitted simultaneously. Reasonable fits have only been obtained by assuming the formation of $1: 1$ and $1: 2(\mathrm{H}: \mathrm{G})$ complexes. The results indicate that in all cases macrocycles 2-4 exhibited considerable binding constants towards positively charged organic ions (Table 2), albeit with moderate selectivity.
Table 2 Association constants obtained by non-linear fitting of NMR data $\left(\mathrm{CDCl}_{3}, 298 \mathrm{~K}\right)$

\begin{tabular}{|c|c|c|c|c|}
\hline & \multicolumn{2}{|l|}{ rac-5 } & \multicolumn{2}{|l|}{6} \\
\hline & $\log \beta_{1}$ & $\log \beta_{2}$ & $\log \beta_{1}$ & $\log \beta_{2}$ \\
\hline 2 & 1.55 & 3.97 & 2.32 & 4.92 \\
\hline 3 & 1.99 & 3.93 & 1.53 & 3.96 \\
\hline 4 & 3.08 & 4.50 & 1.63 & 4.88 \\
\hline
\end{tabular}

\section{Experimental}

2

To a solution of $1 \mathrm{a}(7.5 \mathrm{mmol}, 1.035 \mathrm{~g})$ and $1 \mathrm{~b}(2.5 \mathrm{mmol}$, $0.47 \mathrm{~g})$ in DCE (100 ml), paraformaldehyde ( $10 \mathrm{mmol}, 0.3 \mathrm{~g})$ and TFA $(5 \mathrm{ml})$ were added. The solution was refluxed for $12 \mathrm{~h}$. During the reaction the colour changed from colourless to dark purple. The reaction was cooled down to $\mathrm{rt}$ and excess of $\mathrm{Na}_{2} \mathrm{CO}_{3}$ was added in order to neutralize TFA. The mixture was filtered off and evaporated to dryness. The product was purified by chromatography ( $30 \mathrm{~g}$ silica gel, $\mathrm{CHCl}_{3} /$ ethyl acetate from $100: 0$ to 100 : 2). Yield: $47 \%(0.764 \mathrm{~g}) .{ }^{1} \mathrm{H}$ NMR $\left(\mathrm{CDCl}_{3}, 400 \mathrm{MHz}, 298 \mathrm{~K}\right)$ : $7.99\left(\mathrm{~d}, 1 \mathrm{H},{ }^{3} \mathrm{~J}=9 \mathrm{~Hz}\right), 7.11\left(\mathrm{dd}, 1 \mathrm{H},{ }^{3} \mathrm{~J}=9 \mathrm{~Hz},{ }^{4} \mathrm{~J}=2 \mathrm{~Hz}\right), 6.98(\mathrm{~d}, 1 \mathrm{H}$, $\left.{ }^{4} J=2 \mathrm{~Hz}\right) ; 6.81(\mathrm{~s}, 1 \mathrm{H}), 6.47(\mathrm{~s}, 3 \mathrm{H}), 5.98(\mathrm{~s}, 1 \mathrm{H}), 5.84(\mathrm{~s}, 1 \mathrm{H}), 5.77(\mathrm{~s}$, $1 \mathrm{H}), 4.07$ (s, 2H), $3.95(\mathrm{~s}, 2 \mathrm{H}), 3.90(\mathrm{~s}, 3 \mathrm{H}), 3.89(\mathrm{~s}, 3 \mathrm{H}), 3.86(\mathrm{~s}, 3 \mathrm{H})$, $3.85(\mathrm{~s}, 3 \mathrm{H}), 3.80(\mathrm{~s}, 3 \mathrm{H}), 3.78(\mathrm{~s}, 3 \mathrm{H}), 3.74(\mathrm{~s}, 3 \mathrm{H}), 3.65(\mathrm{~s}, 2 \mathrm{H}), 3.64$ (s, 3H), 3.60 (s, 2H), 3.22 (s, 3H). ${ }^{13} \mathrm{C} \mathrm{NMR}\left(\mathrm{CDCl}_{3}, 100 \mathrm{MHz}, 298 \mathrm{~K}\right)$ : 157.02, 156.93, 156.88, 155.99, 155.96, 155.88, 155.48, 153.15, 133.82, 132.81, 131.53, 131.22, 129.20, 128.67, 125.27, 123.88, 123.40, 121.54, 120.80, 120.63, 119.81, 119.61, 119.53, 117.28, 104.01, 95.15, 94.49, 94.34, 62.06, 55.81, 55.70, 55.65, 55.64, 55.48, 55.34, 55.08, 31.82, 28.72, 28.54, 28.16. MS ( $\mathrm{m} / \mathrm{z})$ : HRMS (ESI) calcd for $\mathrm{C}_{40} \mathrm{H}_{42} \mathrm{O}_{8} \mathrm{Na}\left([\mathrm{M}+\mathrm{Na}]^{+}\right)$673.2777, found 673.2767.

\section{3 and 4}

To a solution of $\mathbf{1 b}(5 \mathrm{mmol}, 0.94 \mathrm{~g})$ in $\mathrm{CHCl}_{3}(50 \mathrm{ml})$, paraformaldehyde ( $5 \mathrm{mmol}, 0.15 \mathrm{~g})$ and TFA $(5 \mathrm{ml})$ were added. The reaction was refluxed for $12 \mathrm{~h}$. During the reaction the colour changed from colourless to dark purple. The reaction was cooled down to rt and excess of $\mathrm{Na}_{2} \mathrm{CO}_{3}$ was added in order to neutralize TFA. The mixture was filtered off and evaporated to dryness. The products were isolated by chromatography ( $30 \mathrm{~g}$ silica gel, $\mathrm{CHCl}_{3} /$ ethyl acetate from $100: 0$ to $100: 2)$. Yield: $3: 15 \%(150 \mathrm{mg})$ and $4: 15 \%(152 \mathrm{mg})$. 3: ${ }^{1} \mathrm{H}$ NMR (400 MHz, $\left.298 \mathrm{~K}\right): 7.97\left(\mathrm{~d}, 4 \mathrm{H},{ }^{3} \mathrm{~J}=9 \mathrm{~Hz}\right), 7.16(\mathrm{~d}, 4 \mathrm{H}$, $\left.{ }^{4} J=2 \mathrm{~Hz}\right), 7.15\left(\mathrm{dd}, 4 \mathrm{H},{ }^{3} J=9 \mathrm{~Hz},{ }^{4} J=2 \mathrm{~Hz}\right), 6.69(\mathrm{~s}, 4 \mathrm{H}), 4.37$ (s, 8H), 3.76 (s, 12H), 3.44 (s, 12H). ${ }^{13} \mathrm{C}$ NMR (100 MHz, $\left.298 \mathrm{~K}\right)$ : 157.61, 152.72, 133.45, 131.42, 129.49, 124.75, 124.21, 123.27, 117.78, 103.55, 61.76, 55.22, 32.16 MS ( $\mathrm{m} / \mathrm{z}$ ): HRMS (ESI) calcd for $\mathrm{C}_{52} \mathrm{H}_{48} \mathrm{O}_{8} \mathrm{Na}\left([\mathrm{M}+\mathrm{Na}]^{+}\right)$823.3231, found 823.3247.

\section{4}

${ }^{1} \mathrm{H}$ NMR (400 MHz, $\left.298 \mathrm{~K}\right): 8.13\left(\mathrm{~d}, 1 \mathrm{H},{ }^{3} J=9 \mathrm{~Hz}\right), 8.10(\mathrm{~d}, 1 \mathrm{H}$, $\left.{ }^{3} J=9 \mathrm{~Hz}\right), 7.82\left(\mathrm{~d}, 1 \mathrm{H},{ }^{3} J=9 \mathrm{~Hz}\right), 7.77\left(\mathrm{~d}, 1 \mathrm{H},{ }^{3} J=9 \mathrm{~Hz}\right), 7.36(\mathrm{~m}$, $2 \mathrm{H}), 7.23(\mathrm{~m}, 2 \mathrm{H}), 6.97(\mathrm{~m}, 1 \mathrm{H}), 6.96(\mathrm{~s}, 1 \mathrm{H}), 6.90\left(\mathrm{~d}, 1 \mathrm{H},{ }^{4} J=2 \mathrm{~Hz}\right)$, $6.86(\mathrm{~s}, 1 \mathrm{H}), 6.83\left(\mathrm{~d}, 1 \mathrm{H},{ }^{4} J=2 \mathrm{~Hz}\right), 6.31(\mathrm{~s}, 1 \mathrm{H}), 6.22(\mathrm{~s}, 1 \mathrm{H})$, $4.52(\mathrm{~s}, 2 \mathrm{H}), 4.35(\mathrm{~s}, 2 \mathrm{H}), 4.29(\mathrm{~s}, 2 \mathrm{H}), 4.21(\mathrm{~s}, 2 \mathrm{H}), 4.01(\mathrm{~s}, 3 \mathrm{H})$, 3.99 (s, 3H), 3.94 (s, 3H), 3.93 (s, 3H), 3.59 (s, 3H), 3.50 (s, 3H), 
3.04 (s, 3H), 2.82 (s,3H). ${ }^{13} \mathrm{C}$ NMR (100 MHz, $\left.298 \mathrm{~K}\right):$ 157.74, 157.71, 157.58, 157.28, 153.52, 153.42, 152.60, 151.79, 133.87, 133.30, 133.24, 133.08, 131.98, 131.78, 131.23, 130.73, 130.23, 128.34, 127.16, 126.34, 125.79, 125.38, 124.78, 124.40, 124.38, 124.27, 124.25, 124.03, 123.41, 123.30, 123.14, 122.34, 117.95, 117.80, 117.42, 117.20, 104.23, 104.17, 102.62, 102.61, 99.99, 61.66, 61.62, 61.43, 55.34, 55.28, 55.22, 55.03, 35.33, 32.85, 31.61, 27.88. MS ( $\mathrm{m} / \mathrm{z}$ ): HRMS (ESI) calcd for $\mathrm{C}_{52} \mathrm{H}_{48} \mathrm{O}_{8} \mathrm{Na}\left([\mathrm{M}+\mathrm{Na}]^{+}\right)$823.3231, found 823.3239.

\section{Crystal data for 4}

$\mathrm{C}_{52} \mathrm{H}_{48} \mathrm{O}_{8} \cdot \mathrm{CH}_{2} \mathrm{Cl}_{2}, M=885.83,0.25 \times 0.07 \times 0.07 \mathrm{~mm}^{3}$, triclinic, space group $P \overline{1}$ (No. 2), $a=12.8554(6) \AA, b=13.0685(6) \AA$, $c=13.4125(6) \AA, \alpha=85.321(4)^{\circ}, \beta=83.005(4)^{\circ}, \gamma=82.019(4)^{\circ}$, $V=2210.08(18) \AA^{3}, Z=2, D_{\text {c }}=1.331 \mathrm{~g} \mathrm{~cm}^{-3}, F_{000}=932$, SuperNova, Dual, Cu at zero, Eos, CuK $\alpha$ radiation, $\lambda=1.54178 \AA$, $T=173(2) \mathrm{K}, 2 \theta_{\max }=144.6^{\circ}, 33685$ reflections collected, 8567 unique $\left(R_{\text {int }}=0.0493\right)$. Final GooF $=1.033, R_{1}=0.0616, \mathrm{w} R_{2}=0.1655$, $R$ indices based on 5928 reflections with $I>2 \sigma(I)$ (refinement on $F^{2}$ ), 576 parameters, 0 restraints. Lp and absorption corrections applied, $\mu=1.784 \mathrm{~mm}^{-1}$. CCDC 1474998.

\section{Conclusions}

There is a continuing need for new semi-rigid macrocyclic compounds for the construction of new supramolecular systems and for their further modifications and application as "biased" architectures. $^{21,22}$ Following these needs we have demonstrated the synthesis of two new regioisomeric calix[4]naphthalenes, by a onestep condensation of 1,6-dimethoxynaphthalene with formaldehyde catalysed by Brønsted acid (TFA). Additionally, we have also shown the first example of a hybrid[ $n]$ arene containing a 1,6-dimethoxynaphthalene unit and 1,3-dimethoxybenzene units obtained by a simple, one-pot condensation. The newly obtained macrocycles exhibit pronounced affinities for organic cations.

\section{Acknowledgements}

This work was supported by the National Science Center (grant UMO-2013/09/N/ST5/00907).

\section{Notes and references}

1 Supramolecular Chemistry: From Molecules to Nanomaterials, ed. J. W. Steed and P. A. Gale, Wiley, 2012.
2 T. Ogoshi, S. Kanai, S. Fujunami, T. Yamagishi and Y. Nakamoto, J. Am. Chem. Soc., 2008, 130, 5022.

3 S. T. Schneebeli, C. Cheng, K. J. Hartlieb, N. L. Strutt, A. A. Sarjeant, C. L. Stern and J. F. Stoddart, Chem. - Eur. J., 2013, 19, 3860.

4 T. Boinski, A. Cieszkowski, B. Rosa and A. Szumna, J. Org. Chem., 2015, 80, 3488.

5 Z. Zhang, J. M. Lim, M. Ishida, V. V. Roznyatovskiy, V. M. Lynch, H. Y. Gong, X. Yang, D. Kim and J. L. Sessler, J. Am. Chem. Soc., 2012, 134, 4076.

6 J. L. Sessler, W. S. Cho, V. Lynch and V. Kral, Chem. - Eur. J., 2002, 8, 1134.

7 G. Cafeo, F. H. Kohnke, G. L. La Torre, M. F. Parisi, R. P. Nascone, A. J. P. White and D. J. Williams, Chem. Eur. J., 2002, 8, 3148.

8 M. Y. Song, H. K. Na, E. Y. Kim, S. J. Lee, K. I. Kim, E. M. Baek, H. S. Kim, D. K. Ana and C. H. Lee, Tetrahedron Lett., 2004, 45, 299.

9 J. Cho, S. Lee, S. Hwang, S. H. Kim, J. S. Kim and S. Kim, Eur. J. Org. Chem., 2013, 4614.

10 F. Troisi, L. Mogavero, C. Gaeta, E. Gavuzzo and P. Neri, Org. Lett., 2007, 9, 915.

11 P. Yang, Y. Jian, X. Zhou, G. Li, T. Deng, H. Shen, Z. Yang and Z. Tian, J. Org. Chem., 2016, 81, 2974.

12 M. Ashram, S. Mizyed and P. E. Georghiou, J. Org. Chem., 2001, 66, 1473; S. Mizyed, P. R. Tremaine and P. E. Georghiou, J. Chem. Soc., Perkin Trans. 2, 2001, 3; P. E. Georghiou, S. Mizyed and S. Chowdhury, Tetrahedron Lett., 1999, 40, 611.

13 P. E. Georghiou, M. Ashram, Z. Li and S. G. Chaulk, J. Org. Chem., 1995, 60, 7284.

14 S. Chowdhury and P. E. Georghiou, J. Org. Chem., 2002, 67, 6808. 15 B. J. Shorthill, R. G. Granucci, D. R. Powell and T. E. Glass, J. Org. Chem., 2002, 67, 904.

16 B. J. Shorthill and T. E. Glass, Org. Lett., 2001, 3, 577.

17 B.-L. Poh, C. S. Lim and K. S. Khoo, Tetrahedron Lett., 1989, 30, 1005.

18 T. Boinski and A. Szumna, Tetrahedron, 2012, 68, 9419.

19 A. Szumna, Chem. Soc. Rev., 2010, 39, 4274.

20 C. Frassineti, L. Alderighi, P. Gans, A. Sabatini, A. Vacca and S. Ghelli, Anal. Bioanal. Chem., 2003, 376, 1041.

21 J. L Atwood, L. J. Barbour and A. Jerga, Proc. Natl. Acad. Sci. U. S. A., 2002, 99, 4837.

22 D. A. Fowler, A. S. Rathnayake, S. Kennedy, H. Kumari, C. M. Beavers, S. J. Teat and J. L. Atwood, J. Am. Chem. Soc., 2013, 135, 12184. 